Plasma Science and Applications (ICPSA 2013)

International Journal of Modern Physics: Conference Series

Vol. 32 (2014) 1460345 (8 pages)

(C) The Author

DOI: $10.1142 / \mathrm{S} 2010194514603457$

\title{
Gliding arc triggered microwave plasma arc at atmospheric pressure for coal gasification application
}

\author{
Vishal Jain, A. Visani, C. Patil, B. K. Patel, P. K. Sharma, P. I. John, S. K. Nema \\ Institute for Plasma Research, Bhat, Gandhinagar, Gujarat, India \\ vishal@ipr.res.in
}

Published 13 August 2014

\begin{abstract}
Plasma torch is device that efficiently converts electrical energy in to thermal energy for various high temperature applications. The conventional plasma torch comprises of consumable electrodes namely anode and cathode electrodes. The replacement of these electrodes is a complex process owing to its cooling and process shut down requirements. However, microwave plasma arc is electrode-less plasma arc system that is an alternative method to conventional arc technology for generating plasma arc. In this technique, microwave power is efficiently coupled to generate plasma arc by using the property of polar molecule to absorb microwave power. The absorption of microwave power is in form of losses due to intermolecular friction and high collisions between the molecules. This is an efficient method because all microwave power can be absorbed by plasma arc. The main feature of microwave plasma arc is its large uniform high temperature column which is not possible with conventional arc discharge methods. Such type of plasma discharge is very useful in applications where sufficient residence time for treat materials is required. Microwave arc does not require any consumable electrodes and hence, it can be operated continuously that makes it very useful for hazardous effluent treatment applications. Further, microwave cannot ionize neutral particles at atmospheric pressure and hence, a gliding arc is initiated between two thin electrodes in the cavity by applying very low power high voltage $(3 \mathrm{kV})$ $\mathrm{AC}$ source. In this report, the method for generating microwave arc of $1 \mathrm{~kW}$ power using commercial microwave oven is elaborated.
\end{abstract}

Keywords: Microwave arc; Plasma; Coal Gasification.

\section{Introduction}

Plasma torch is efficient device for converting electrical energy to thermal energy for many thermal plasma applications ${ }^{1}$. These plasma torches generate plasma arc between electrodes that are consumable materials. Replacement of these consumable electrodes is a complex process as it is susceptible to water leaking in case of metallic electrodes. The graphite electrode method requires no cooling but it has limitations to applications in non-oxidizing environment ${ }^{2}$. Therefore, RF Plasma torch or Microwave plasma torch are

This is an Open Access article published by World Scientific Publishing Company. It is distributed under the terms of the Creative Commons Attribution 3.0 (CC-BY) License. Further distribution of this work is permitted, provided the original work is properly cited. 


\section{Jain et al.}

alternative to AC or DC arc technology. However, electro-thermal efficiency of RF plasma torch is limited to only $40 \%$ or even lesser because of the cooling requirement of the coils and unavoidable magnetic leakages. But atmospheric pressure microwave plasma jet has shown great potential because of its efficiency and electrode-less operation. It is very useful for applications like material treatment and processing, space applications etc. ${ }^{3,4}$ Microwave plasma torch has also been applied for diamond synthesis ${ }^{5,6}$. Among all research work on microwave, the microwave plasma arc with waveguide fed applicator is most common that has been applied for different applications 7-12. The microwave plasma arc has also been applied for treatment of gasoline for hydrogen generation ${ }^{13,14}$ and abatement of $\mathrm{CF}_{4}$ and $\mathrm{SF}_{6}$ removal ${ }^{15,16}$. Hong also did work on decomposition of phosgene ${ }^{17}$ and elimination of chemical and biological warfare agent $^{18,19}$. Atmospheric microwave application for E. Coli sterilization has been carried out by Park $^{20}$. The microwave plasma torch is also explored for welding applications initiated at Liverpool ${ }^{21}$. Microwave plasma torch is found most suitable for coal gasification from low grade $\mathrm{coal}^{22}$ because of its large and uniform high temperature column in the discharge tube that gives enough residence time for the reactions for gasification.

In this report, the microwave plasma arc generation is emphasized using a commercial microwave source of $1 \mathrm{~kW}$ rating. The plasma arc is generated in a fused quartz tube with Ar and Steam gas flow from the back side. The coal powder is fed inside the quartz tube from the top port connected to screw powder feeding chamber to maintain a flow rate of $18 \mathrm{~g} / \mathrm{min}$ in order to achieve nearly $1 \mathrm{~kg} / \mathrm{hr}$ feed rate. The magnetron often used for commercial microwave oven was connected to an external waveguide to comprise a microwave source. The microwave power is then transferred to quartz tube via directional coupler, applicator and 3 stub tuner between the directional coupler and applicator.

Microwave plasma arc coal gasification technology has following advantages:

- Cleanest Coal technology (lower SOx, NOx, PM, Solid waste, Waste water).

- Proven Technology: Almost 150 plants running in the world with IGCC.

- Environmentally acceptable (NRDC, CATF).

- Only bridge from Coal to Hydrogen.

- Microwave power can simply be added in form of an array to the discharge tube.

In microwave coal gasification, the large plasma column of nearly $2500 \mathrm{deg} \mathrm{C}$ is achieved and coal powder is processed through microwave plasma arc in presence of Oxygen/Argon and steam. This process generates synthesis gas (also called as syngas) which is a mixture of hydrogen and carbon mono-oxide. This syngas can be used for either direct heating in the boilers or for electrical power generation through IGCC system. The details of the set up are mentioned in experimental set up that is followed by results and discussions and conclusions. 


\section{Experimental Set up}

A commercial magnetron is mounted in a WR284 waveguide adapter \& is used as a microwave source. This arrangement directs the microwave power in the axial direction of the waveguide. It is then connected to a directional coupler that has provision to attach detector for measurement of forward and reflected power. The other end of the directional coupler is connected to an electrical field enhancer called a microwave transformer that increases the electric field of the microwave by reducing the breadth of the waveguide to nearly $1 / 5^{\text {th }}$ of its original value at directional coupler junction. The transformer matches the impedance of the source to the cavity ensuring maximum transfer of power from the source to the cavity. Hence, the electric field also increases by five times. The magnetron is placed on waveguide adapter about quarter wavelength $\left(\lambda_{\mathrm{g}} / 4\right)$ away from the short end. Here $\lambda_{\mathrm{g}}$ is given by following relation.

$$
\lambda g=\frac{\lambda}{\sqrt{1+\left(\frac{\lambda}{2 \mathrm{x}}\right)^{2}}}
$$

Where $\lambda_{\mathrm{g}}$ is the microwave wavelength in centimeter, $\mathrm{x}$ is the width of the microwave waveguide in centimeter.

Finally, microwave transformer is connected to an applicator that applies microwave power to the discharge tube inside the cavity. The discharge tube of $30 \mathrm{~mm}$ outer diameter and $25 \mathrm{~mm}$ inner diameter made of fused quartz holds all gas inlet ports, powder feeder port and gliding arc electrode ports.

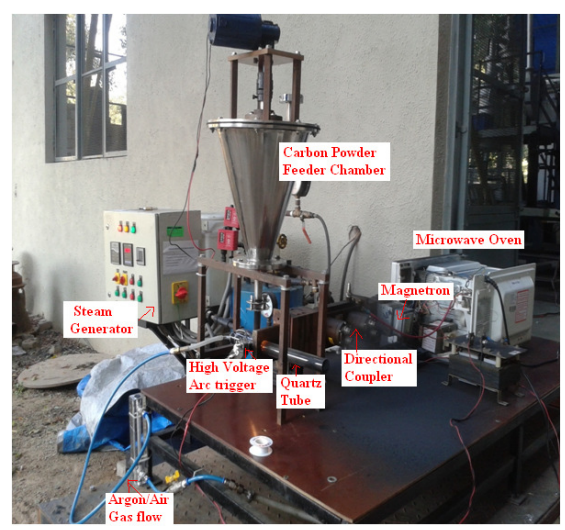

Fig. 1. Microwave Plasma arc experimental set up.

The experimental set up for coal gasification using microwave plasma arc is shown in Fig. 1. The system comprises of boiler for steam generation, Argon/Air flow arrangement, Carbon powder feeder chamber, high voltage transformer for initial trigger for gliding arc, fused quartz tube etc.

As shown in the schematic in Fig. 2, the initial electric discharge is created by a high voltage gliding arc between two electrodes in the fused quartz tube. This gliding arc 


\section{Jain et al.}

discharge generates polar molecules after ionization that absorbs the microwave power immediately to form $1 \mathrm{~kW}$ microwave plasma arc. The quartz tube is routed through a $30 \mathrm{~mm}$ diameter hole in the applicator. The other end of applicator is closed by a copper plate. Carbon powder in the quartz tube is fed through a screw feeding mechanism at the rate of $18 \mathrm{gm}$ per minute. Syngas is generated by the reaction of carbon with steam at nearly $2000 \mathrm{deg} \mathrm{C}$ column. The optimization of process can generate a good quality syngas that can be taken to a gas collection chamber for analysis purpose and demonstration of flame at burner.

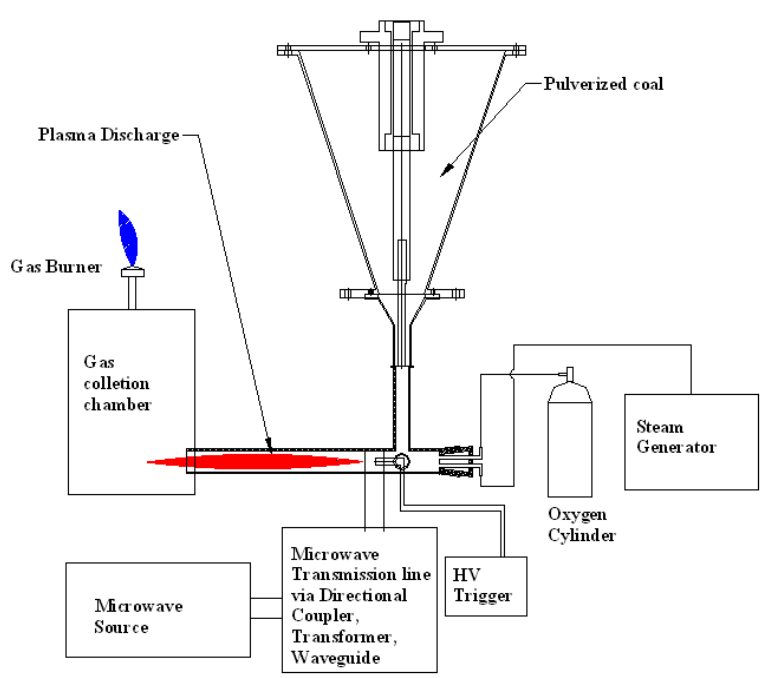

Fig. 2. Schematic of microwave coal gasification experiments.

Generally, in place of gliding arc, external fuel in few SCCM is fed in the discharge tube cavity for creating the initial arc which absorbs the microwave power to convert it into plasma arc. In this report, the high voltage low current gliding arc was used to create the initial arc. The gliding arc avoids use of any other fuel for initial trigger arc generation.

The main objective of the process is to generate a large column of plasma discharge with microwave power and partial coal combustion to convert carbon powder into syngas. This efficiently generates syngas which can be carried to other burner for combustion purpose to study the quality of the gases. The initial microwave power coupling was tested by keeping the fluorescent tube in place of fused quartz tube as shown in the fig. 3(A). 


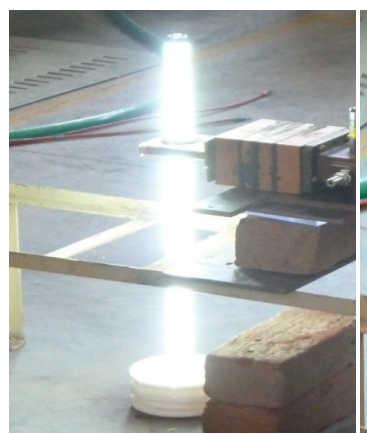

(A)

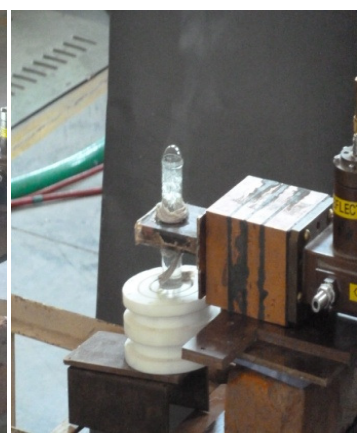

(B)

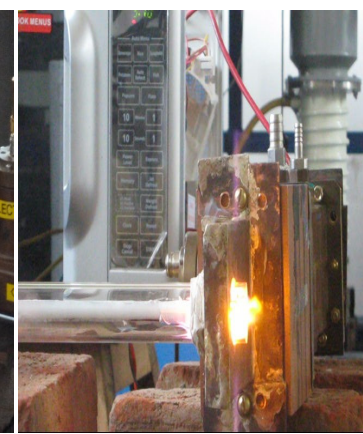

(C)

Fig. 3. Microwave Power couple.

The microwave power coupling was also tested in a water tube kept in the same cavity in place of quartz tube and it was observed that $200 \mathrm{ml}$ of water boiling requires only 10 seconds as shown in Fig. 3(B). Finally, the power coupling with plasma plume was tested with using no carbon powder feed but only Ar and Steam as plasma gen gas with a gliding arc in the cavity. Microwave plasma arc with Ar and Steam under such condition is shown in fig. 3(C). The microwave power coupling with carbon powder feed with steam and air was tested in the discharge tube as shown in Fig. 4.

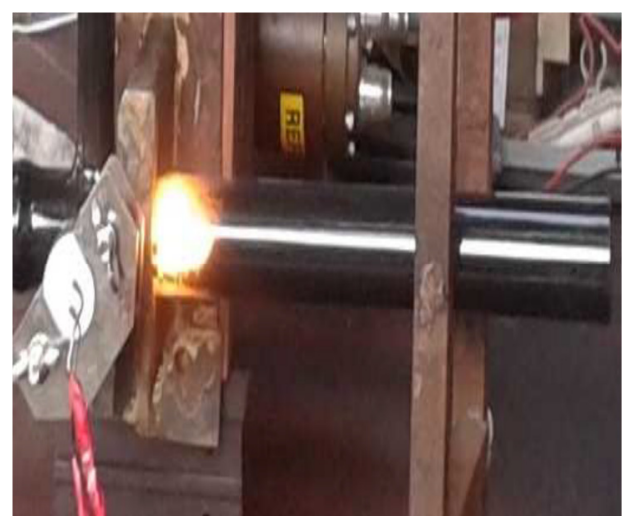

Fig. 4. Microwave Plasma Arc with Carbon powder + Steam + Air flow.

\section{Results and Discussions}

The plasma arc of $1 \mathrm{~kW}$ power was successfully generated using commercial microwave source. It was observed that the position of the source and the center axis of the discharge tube plays very important role in reducing the reflected power and thus, increasing the efficiency. OES (Optical Emission Spectroscopy) analysis was done for fluorescent tube discharge and plasma arc discharge that are shown in Fig. 5. The fluorescent tube 


\section{Jain et al.}

discharge shows no UV radiation spectra while microwave plasma arc spectra show the presence of UV, IR spectrum along with the visible light spectrum that also counts for the heating and sterilization application.

Microwave source is also designed for study of other tailored applications for example fragmentation of toxic compounds, Carbon nano powder synthesis, and synthesis of syngas from low grade coal, diamond Decolorization etc. These studies will be carried out and if required more microwave power can be coupled with taking anther tapered cavity in series with same discharge tube.
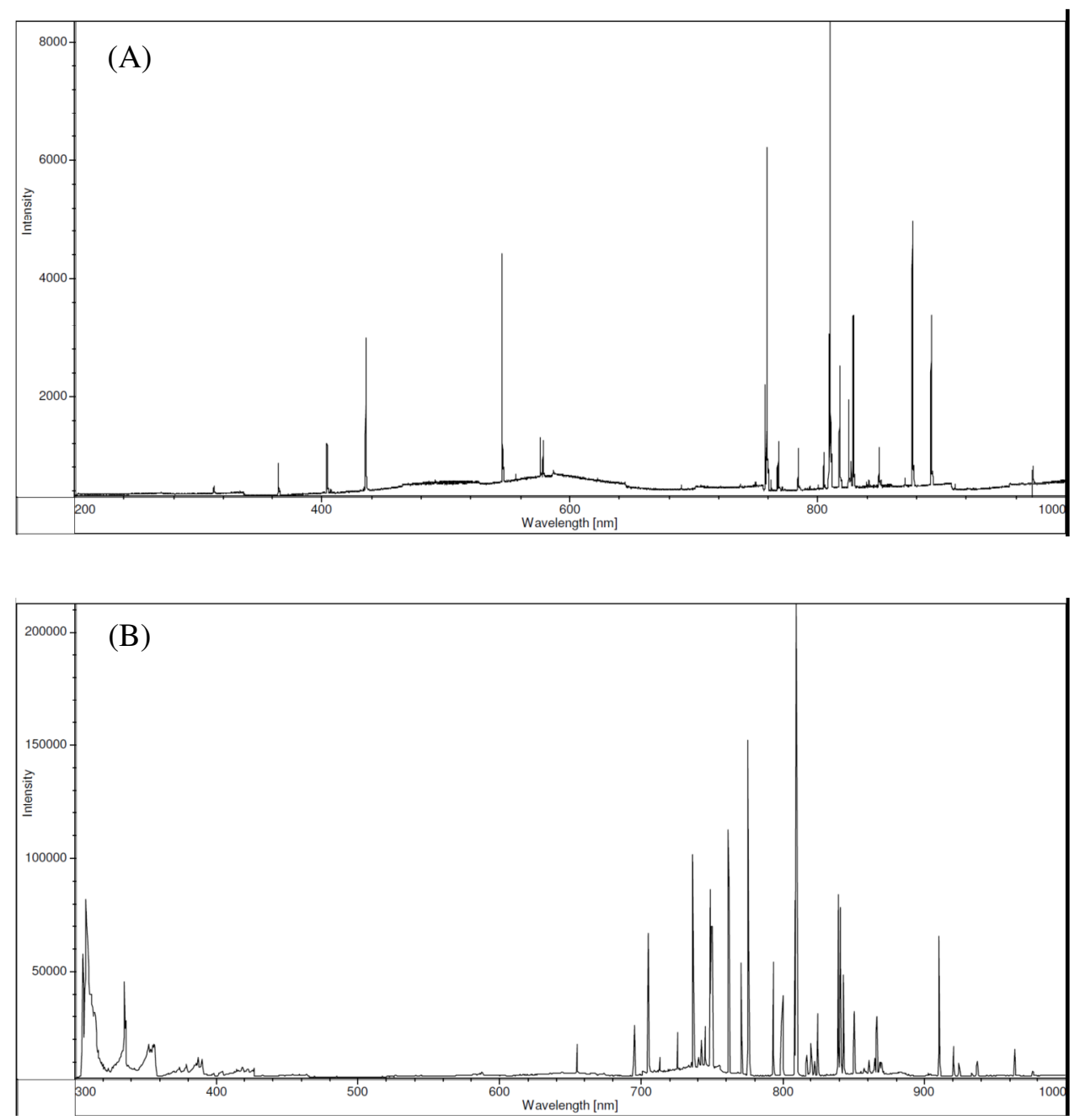

Fig. 5. OES spectra (A) fluorescent tube discharge (B) Plasma Arc discharge. 


\section{Conclusion}

Microwave power can generate electrode-less plasma arc in a very efficient manner. The efficiency can be maximized up to $100 \%$ because the plasma can absorb forward as well as all reflected power if the position of the quartz tube is maintained properly at quarter wavelength of microwave from end plate of the applicator. Microwave plasma arc is most efficient method for converting electrical energy into thermal energy. The problem associated with radiation can be completely avoided by proper shielding of quartz tube using mesh across the quartz tube.

\section{References}

1. S. P. Kuo, M. Rubinraut, S. Popovic and D. Bivolaru, IEEE Transactions on Plasma Science 34 (6), 2537-2544 (2006).

2. Innovative Technology Summary Report,U. S. Department of Energy DOE/EM (0431) (1999).

3. A. I. Al-Shamma'a, S. R. Wylie, J. Lucas and Y. Jiu Dun, IEEE Transactions on Plasma Science 30 (5), 1863-1871 (2002).

4. S. R. Wylie, A. I. Al-Shamma'a and J. Lucas, IEEE Transactions on Plasma Science 33 (2), 340-341 (2005).

5. Y. Mitsuda, T. Yoshida and K. Akashi, Review of Scientific Instruments 60 (2), 249-252 (1989).

6. C.-C. Ting, T.-F. Young and C.-S. Jwo, The International Journal of Advanced Manufacturing Technology 34 (3-4), 316-322 (2007).

7. M. Moisan, G. Sauve, Z. Zakrzewski and J. Hubert, Plasma Sources Science and Technology 3 (4), 584 (1994).

8. W. C. L. Young S. Bae, Kyung B. Ko, Yong H. Lee, Won Namkung, Moo H. Cho, Journal of the Korean Physical Society 48 (1), 67-74 (2006).

9. S. P. Kuo, D. Bivolaru, H. Lai, W. Lai, S. Popovic and P. Kessaratikoon, IEEE Transactions on Plasma Science 32 (4), 1734-1741 (2004).

10. S. Y. Moon, W. Choe, H. S. Uhm, Y. S. Hwang and J. J. Choi, Physics of Plasmas 9 (9), 4045-4051 (2002).

11. J. Pollak, M. Moisan and Z. Zakrzewski, Plasma Sources Sci. Technol. 16 (13), 310-323 (2007).

12. J. H. Kim, Y. C. Hong, H. S. Kim and H. S. Uhm, Journal of the Korean Physical Society 42 , 876-879 (2003).

13. H. Sekiguchi and Y. Mori, Thin Solid Films 435 (1-2), $44-48$ (2003).

14. S. Nomura, H. Toyota, M. Tawara, H. Yamashita and K. Matsumoto, Applied Physics Letters 88 (23), 231502-231503 (2006).

15. Y. C. Hong, J. H. Kim and H. S. Uhm, Physics of Plasmas 10 (8), 3410-3414 (2003).

16. M. Radoiu and S. Hussain, J. Hazard. Mater. 164, 39-45 (2009).

17. Y. C. Hong, H. S. Uhm, H. S. Kim, M. J. Kim, S. H. Han, S. C. Ko and S. K. Park, IEEE trans. Plasma Sci. 33 (2), 958-963 (2005).

18. Y. C. Hong, J. H. Kim and H. S. Uhm, Physics of Plasmas 11 (2), 830-835 (2004).

19. W. Lai, H. Lai, S. P. Kuo, O. Tarasenko and K. Levon, Phys. Plasmas 12 (2), 023501023506 (2005). 
20. B. J. Park, K.Takatori, M. H. Lee, D.-W. Han, Y. I. Woo, H. J. Son, J. K. Kim, K.-H. Chung, S. O. Hyunf and J.-C. Park, Surf. Coat. Technol. 201, 5738-5741 (2007).

21. D. Leather, Ph.D. Dissertation, The University of Liverpool, Liverpool U.K. (1994).

22. Y. C. Hong, S. J. Lee, D. H. Shin, Y. J. Kim, B. J. Lee, S. Y. Cho and H. S. Chang, Energy 47 (1), 36-40 (2012). 